Portland State University

PDXScholar

5-1997

\title{
The Generalization of Stridency from Treated to Untreated Misarticulated Phonemes
}

\author{
Kathleen Ann Ozanich \\ Portland State University
}

Follow this and additional works at: https://pdxscholar.library.pdx.edu/open_access_etds

Part of the Speech and Hearing Science Commons

Let us know how access to this document benefits you.

\section{Recommended Citation}

Ozanich, Kathleen Ann, "The Generalization of Stridency from Treated to Untreated Misarticulated Phonemes" (1997). Dissertations and Theses. Paper 5751.

https://doi.org/10.15760/etd.7620

This Thesis is brought to you for free and open access. It has been accepted for inclusion in Dissertations and Theses by an authorized administrator of PDXScholar. Please contact us if we can make this document more accessible: pdxscholar@pdx.edu. 
The abstract and thesis of Kathleen Ann Ozanich for the Master of Arts in speech Communication: Speech and Hearing Sciences were presented March 13, 1997, and accepted by the thesis committee and the department.

COMMITTEE APPROVALS:
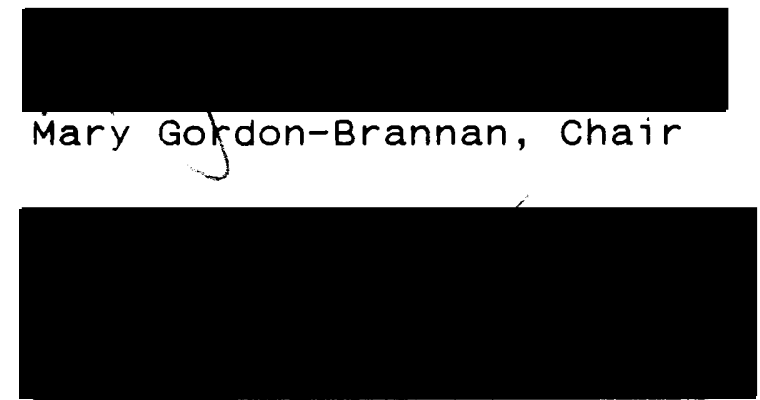

John Tetnowski

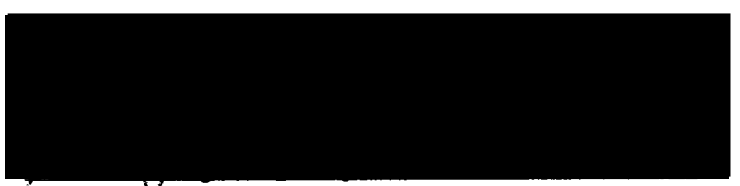

Tucker childs Representative, Office of Graduate studies

DEPARTMENT APPROVAL:

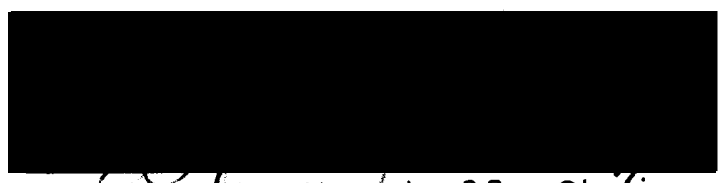

Stephen/A. Koslokoff, Chair Department of speech Communication

$* * * * * * * * * * * * * * * * * * * * * * * * * * * * * * * * * * * * * * * * * * * * * * * * * * * * * * * *$ ACCEPTED FOR PORTLAND STATE UNIVERSITY BY THE LIBRARY by on

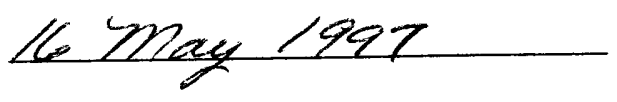


ABSTRACT

An abstract of the thesis of Kathleen Ann Ozanich for the Master of Arts in speech Communication: Speech and Hearing Sciences presented March 13, 1997.

Tit1e: The Generalization of Stridency from Treated to Untreated Misarticulated Phonemes.

This single-subject study was developed to investigate the potential of treating one misarticulated strident phoneme to induce generalization to other misarticulated strident phonemes. One male, age 4 years 4 months, was trained on /s/ in words. A training program, modified from the Hodson and Paden (1991) phonological cycling approach, was used. Two untreated phonemes from separate and distinct sound classes were monitored as control sounds for across-feature class change. A total of 24 treatment sessions of 50 minutes each were provided.

The results from the pretest and posttest showed an increase of $51 \%$ correct stridency production for all untreated stridents and an $8 \%$ increase for the treated /s/. Results of probe measurements showed $85 \%$ correct productions of /s/ in untreated words on several occasions. The change in the untreated control sounds 
was varied. One phoneme showed no change; another improved 100\%. A positive transfer of learning from treated to untreated stridents was exhibited by this subject. 
THE GENERALIZATION OF STRIDENCY FROM TREATED TO UNTREATED MISARTICULATED PHONEMES

by

KATHLEEN ANN OZANICH

A thesis submitted in partial fulfillment of the requirements for the degree of

\author{
MASTER OF ARTS \\ in \\ SPEECH COMMUNICATION: \\ SPEECH AND HEARING SCIENCES
}

\author{
Portland State University \\ 1997
}


TABLE OF CONTENTS

PAGE

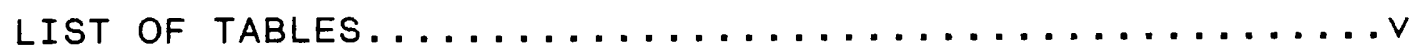

LIST OF FIGURES.......................

CHAPTER

I INTRODUCTION AND STATEMENT OF PURPOSE $\ldots \ldots \ldots 1$

Introduction.................

Statement of Purpose..............

Definition of Terms.............4

I I REVIEW OF THE Literature..............

Speech Sound Treatment Approaches......6

Feature Generalization............10

summary...................22

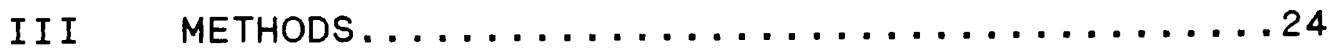

Subject selection...............24

Instrumentation................25

Procedures..................27

Treatment Target Selection......27

Reliability.................27

Treatment Protocol...........28

Word selection...........28

Perception Practice.........30

Production Practice..........30

Home Program............... 31

Probes..................... 32 
Data Analysis.....................

Pre- and Posttest Comparison......33

IV RESULTS AND DISCUSSION.............. 36

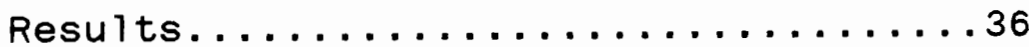

Results for A11 Sounds.........37

Voiced and Voiceless stridents...44

Individual Sound Changes.......42

Probe....................44

Discussion....................45

Generalization of stridency.....45

The Treated Phoneme /s/.......47

Untreated Control Sounds........50

Untreated Strident Changes......51

Individual Sound Changes.......552

summary................... . . . 55

$\checkmark \quad$ SUMMARY AND IMPLICATIONS............. 57

summary.................... 57

Implications.......................

Clinical Implications..........58

Research Implications.........60

REFERENCES.........................63

APPENDICES.........................66 
1 Percent of Correct Productions of the Individual Treated and Untreated Phonemes.........................43 


\section{LIST OF FIGURES}

FIGURES

PAGE

1 Percent of Correct Production of

Treated and Untreated Stridents...........39

2 Percent of Correct Responses of Non-

stridents.......................40

3 The Percent of correct Productions of

the Untreated Voiceless and Voiced

Strident Phonemes..................41

4 Percent of Correct Productions of /s/

in Untreated Words from July through

August.........................45 
CHAPTER I

\section{INTRODUCTION AND STATEMENT OF PURPOSE}

\section{Introduction}

One of the most important concerns for speechlanguage pathologists providing services in the field is to be as efficient and effective as possible in the remediation of communication disorders. Invariably, a certain percentage of children with significant articulation/phonological disorders will be part of speech-language pathology caseloads. For these children, communication is especially frustrating. Often they are unintelligible to teachers, peers, and sometimes even to their parents and siblings. In addition to the socialemotional aspects of highly unintelligible speech, it is important to recognize the negative impact a severe speech disorder can have on emergent literacy skills (Hodson, 1994).

It is the responsibility of speech-language pathologists to do assessments, analyses, and make decisions about the most appropriate place to begin remediation for highly unintelligible clients. 
These can be difficult decisions to make. Speechlanguage pathologists need to decide which tests to use, what method of analysis will be appropriate, and what remediation approach will be used. Having an in-depth understanding of the sound patterns in the English language is crucial to the analysis and selection of treatment goals for these clients.

A child's articulation errors may initially seem haphazard and inconsistent as compared to the adult system. However, through careful analysis of the types of sound errors and phonological deviations being used, we may find that there is indeed a rule-based system operating, although it is different from an adult form of communication. Once we have discovered the rule-based system with which the child is operating, we will be able to make some decisions as to the most appropriate goals to select. Specifically, when presented with a child evidencing speech with multiple misarticulations, will it be possible to select a treatment target that will have an effect on several phonemes as a result of common underlying features? This study will contribute to the pool of research necessary to support decisions for the selection of treatment targets in an articulation and/or phonological remediation program. 
Statement of Purpose

The purpose of this study was to address the following question: If a misarticulated or omitted phoneme in a sound class is targeted, will correct production generalize to other misarticulated or omitted phonemes in the same sound class? For example, if a clinician were to target /s/ in treatment, would it lead to improved articulation of other misarticulated stridents such as $/ f /, / v /$, and $/ t S /$ due to acquisition of the stridency feature? A secondary consideration for this study was to determine to what degree generalization may occur to each untreated strident phoneme with regard to voicing. For example, if a voiceless strident (e.g., /s/) was selected to train the feature of stridency, would training generalize equally to voiced (e.g., $/ \mathrm{v} /$, $/ z /$ ), and voiceless (e.g., /f/, /tS/) untrained stridents?

The research hypothesis was: remediation of one strident phoneme will lead to the acquisition of the strident feature in other misarticulated untrained phonemes of this sound class. The corresponding null hypothesis was: remediation of one strident phoneme will not lead to the acquisition of the strident feature in other misarticulated untrained phonemes of this sound class. 
Definition of Terms

The following are terms used for the purpose of this study:

Arresting position: refers to the position of a consonant in a syllable or word during connected speech. For example, $\underline{s}$ is an arrestor in the word houseboat.

Distinctive feature: an articulatory or acoustic element that defines a phoneme. Each phoneme can be thought of as a unique combination of features (Creaghead, Newman, \& Secord, 1989).

Phoneme: a group of phones that are perceived as belonging to the same sound category. The set of phonemes is considered to constitute the discrete speech units of a language (Creaghead et a1., 1989).

Phonological pattern: a grouping within an oral language, such as a sound class, a consonant sequence, or a syllable shape (Hodson \& Paden, 1991).

Phonological process: a regularly occurring deviation in an individual's utterances, usually one that simplifies an adult phonological pattern (Hodson \& Paden, $1991)$

Releasing position: refers to the position of a consonant in a syllable or word during connected speech. For example, $\underline{s}$ is a releaser in the phrase the sun. 
Stridents: consonants characterized by considerable, noisy turbulence caused by forceful airflow striking a hard surface: $/ f, v, s, z, \int, z, t \int, d z /$ (Hodson \& Paden, 1991).

Voiced: refers to speech sounds in which the vocal folds vibrate (Creaghead et a1., 1989).

Voiceless: sounds in which the vocal folds do not vibrate (Creaghead et a1., 1989).

Voicing: phonological process in which voicing is added to voiceless sounds (Creaghead et a 1., 1989) 


\section{CHAPTER I I}

REVIEW OF THE LITERATURE

In the field of speech-language pathology, there are several different approaches to the remediation of articulation and/or phonological disorders. The various approaches share commonalties in their procedures of diagnosis of speech disorders through the use of standardized articulation or phonological tests and informal language samples. However, the process of analysis and selection of treatment targets for remediation varies according to the clinician's philosophy, knowledge, and beliefs about appropriate treatment goals. Three different approaches to the treatment of articulation/phonological disorders have been used throughout the years: the traditional approach, the distinctive features approach, and the phonological processes approach.

Speech Sound Treatment Approaches

Prior to the mid 1970 s, remediation of articulation disorders focused on targeting each individual misarticulated sound in treatment (Hodson \& Paden, 1991) Speech disorders were viewed as phonemic inadequacies 
rather than phonological deviations or sound feature errors. Speech-language pathologists, through testing, obtained a list of sounds mastered and those that were misarticulated. The errors of highly unintelligible children were considered inconsistent or random and it was generally viewed that the misarticulated sounds had not yet been learned by the child; therefore, it was the procedure of choice to teach each individual phoneme (Van Riper, 1939). Such phoneme-oriented programs require a child to perfect every phoneme in isolation, syllables, words, phrases, sentences, and conversation. For children with numerous speech sound errors, this type of program can be an arduous and lengthy process; of ten requiring 5 to 6 years of intervention (Hodson, 1994).

A clinician encountering a child with multiple misarticulations may be inclined to look for a strategy that expedites the remedial process (Creaghead et al., 1989). In 1971, McReynolds and Huston conducted a study that investigated two methods of analyzing the sound errors of highly unintelligible children. The misarticulations of 10 children ranging from 4 years 4 months to 6 years 5 months were analyzed in two ways. First, they counted the number of different phoneme errors. For some children, this amounted to 14 separate phonemes in error $100 \%$ of the time. The second analysis 
involved categorizing the error phonemes according to sound classes by using the 13 distinctive features out 1 ined by Chomsky and Halle (1968). By using this method of analysis, McReynolds and Huston (1971) categorized numerous misarticulated phonemes into a few sound classes. In some cases, certain sound classes were completely lacking from a child's repertoire; hence, all the phonemes containing features from those sound classes were omitted. McReynolds and Huston (1971) speculated that efficiency would be increased in articulation remediation programs if a feature or sound class was targeted, rather than each individual phoneme in error. Such a program would reduce the number of individual phonemes and articulatory responses required by a child. More recent approaches to the remediation of articulation disorders have drawn from the field of 1inguistics (Creaghead et a1., 1989; Hodson, 1994). Unlike the phoneme-oriented approaches that target each individual sound in error, linguistically based approaches focus on the underlying rules or principles that govern the formation and organization of the sounds of a language (Creaghead et a1., 1989). Linguistically based intervention approaches used today can be divided into two major types: (a) distinctive feature approaches and (b) phonological process approaches. 
A distinctive feature approach to remediation of articulation disorders first begins with an in-depth anaiysis of a child's misarticulations using any of a number of systems. With some systems, sounds are analyzed according to their component parts or features, that is, place features, manner features, voicing features, etcetera. In other systems, sounds are analyzed according to sound classes such as nasal/nonnasal, voiced/voiceless, strident/mellow, etcetera. The emphasis in remediation is placed on targeting one underlying feature in error at a time, rather than a phoneme as a whole, as is typical in the traditional approach (creaghead et al., 1989). Often minimal word pairs are used to teach the motor-acoustic and 1 inguistic importance of a sound feature (Creaghead et a1., 1989). Contrasting word pairs, differing in a single sound feature (e.g., tea-key), allows a child to focus on the specific feature in error while at the same time promoting the linguistic importance of the feature change.

A phonological processes approach is similar to the distinctive feature approach in that it requires an indepth analysis of a child's sound errors in order to identify the underlying patterns that characterize a child's sound system. However, rather than targeting an 
individual phoneme or exclusively the underlying features of sounds, a phonological process approach looks at deviant phonological patterns (e.g., final consonant deletion, consonant cluster reduction) as we 11 as some underlying features (e.g., stridency, velars) (Hodson \& Paden, 1991).

Although a distinction is made between the distinctive features and phonological process approaches, there is much overlap (Creaghead et a1., 1989). With both approaches, clinicians attempt to find patterns in the sound errors presented by highly unintelligible children through careful analysis of the speech sample. Remediation plans are then developed that take advantage of the error patterns. The primary advantage of using these types of approaches to analyze and plan remediation is that elimination of a deviant rule or process may result in correcting several phonemes simultaneously, thereby providing a more efficient remediation program for articulation and/or phonological disorders (Creaghead et $a 1 ., 1989)$.

\section{Feature Generalization}

In several research studies, the possibility of correcting multiple phoneme errors through programs based on remediation of the underlying feature or phonological process being used has been explored (Blache, Parsons, \& 
Humphreys, 1981; Coste110 \& Onstine, 1976; McReynolds \& Bennett, 1972; Ruder \& Bunce, 1981; Tyler, Edwards, \& Saxman, 1987).

In 1972, McReynolds and Bennett conducted a study that tested feature generalization from treated misarticulated phonemes to untreated misarticulated phonemes within the same sound class. They performed an analysis of the sound errors using Chomsky and Halle's (1968) distinctive feature analysis and then selected one phoneme to be targeted in the initial and final positions of nonsense syllables. Three subjects who had been involved in a previous study conducted by McReynolds and Huston in 1971 were selected for this study. Their ages were not specifically stated but rather an age range from 4 years 4 months to 6 years 7 months was given. Since the study being discussed here took place approximately 1 year later it can be assumed that the 3 subjects who participated in this study were between the ages of 5 years 4 months and 7 years 7 months.

Each subject was trained on a different sound class. One child was trained to utilize the feature of stridency in the context of the phoneme /f/. Other strident phonemes ( $i . e ., / v, s, z, t S /$ ) were used as the nontargeted control group to test for generalization. A sound from a separate feature class (i.e., / $/$ /), was also 
investigated and served as a control to determine if only the feature being trained would change. The targeted and non-targeted phonemes were all 100\% in error on the baseline as determined through probing each phoneme on The Deep Test of Articulation (McDonald, 1964b). Results of treatment showed that generalization had occurred to untrained phonemes to varying degrees and from nonsense syllables to words on the McDonald Deep Test. On the final probe, the phonemes $/ s, t S /$ were $0 \%$ and $6 \%$ in error, respectively, and the phonemes $/ \mathrm{V}, \mathrm{z} /$ were $53 \%$ and $40 \%$ in error, respectively. No improvement was demonstrated for the $/ \theta /$ phoneme.

Another subject in the McReynolds \& Bennett (1972) study was trained on (+) voicing by contrasting /p/ with /b/ in the initial and final positions of nonsense syllables. The /p/ had been substituted for $93 \%$ of the /b/ words in the initial assessment on the McDonald Deep Test. The voiced plosive phonemes /d,g/ were used as the untrained probes to test for generalization. They were each $100 \%$ in error during initial testing. Again the phoneme $/ \theta /$ was used as a control to test for acrossfeature generalization. Test results indicated a mean decrease in voicing errors from $98 \%$ to $14 \%$ for both the treated and untreated phonemes, with greater improvement in the releasing position of words. The $/ \theta /$ remained 
unimproved.

The third subject in this study was trained on (+) continuancy by contrasting the phoneme $/ S /$ with $/ \mathrm{t} J /$, a (-) continuant that was already a part of the child's repertoire. The trained $/ S /$ and untrained probes $/ s, z, f, v /$ were all 100\% in error on initial testing. Posttesting results showed a mean improvement of $69 \%$ for the trained and untrained phonemes; however, there was a considerable discrepancy in improvement across phonemes. The /S/ and /s/ were on ly $8 \%$ in error, whereas, the $/ z, f, v /$ were $64 \%, 36 \%$, and $40 \%$ in error respectively, on the final assessment. The results from this study indicated that generalization had occurred within the target sound class of $(+)$ continuant. An untrained control phoneme from a separate and distinct feature class was not investigated with this subject.

Coste110 and Onstine (1976) also addressed the issue of generalization from treated to untreated phonemes within the same sound class by targeting an underlying feature. According to Costel10 and Onstine, a program in which features are taught should include production practice that contrasts phonemes differing in the presence or absence of the target feature. In their study, two children, ages 4 years 5 months and 4 years 2 months, were treated for the stopping of continuants. 
Costel10 and Onstine (1976) assessed the accuracy of the children's productions using The Deep Test (McDonald, 1964b) and through an imitative sound production task. Both children substituted stops for most, but not al1, of the continuants. The continuants $/ f /$ and $/ v /$ were used correctly by the children whereas the percent of accurate productions of the continuants $(/ \theta /, / \delta /, / s /, / z /$, and /S/) ranged from o\% to $6 \%$. The treatment targets chosen were $/ \theta /$ and $/ \mathrm{s} /$. These were contrasted with a stop /t/ that was correctly used by the children on the pretest. Results from treatment showed that the feature (t) continuant had generalized to the untrained targets to varying degrees. Posttesting results showed improvement for $/ \mathrm{S} /($ mean $=80 \%$ correct production for both children), /z/ (mean $=90 \%$ correct production for both children), and $/ \% /$ (mean $=48.5 \%$ correct production for both children).

In the studies by McReynolds and Bennett (1972) and Costel10 and Onstine (1976) described above, generalization occurred within sound classes. However, in the McReynolds and Bennett (1972) study, generalization had not occurred equally to the voiced/voiceless cognates within the strident and continuant sound classes. Greater improvement occurred in the voiceless phonemes. In the costello and Onstine 
(1976) study, generalization occurred equally to the voiced and voiceless continuants in the control group with the exception of the phoneme /\%/. One difference between the two studies was that the children in the Costel10 and Onstine (1976) study already had a voiced and voiceless continuant in their repertoires; whereas, the children in the McReynolds and Bennett (1972) study displayed. $100 \%$ error initially in the strident and continuant sound classes.

Ruder and Bunce (1981) also conducted a study based on distinctive feature analysis and feature training to promote the emergence of several phonemes absent from a child's repertoire. The articulation of two subjects was analyzed in terms of the distinctive feature system developed by Chomsky and Halle (1968). Selected treatment targets were trained in isolation, syllables, initial position of words, and two-word phrases. One subject, aged 4 years, produced the consonants /m,b,g/ and some vowels. Through distinctive feature analysis, it was found that the following features were lacking: continuant, strident, coronal, (-) voicing, and high. Training targets $/ \mathrm{k} /$ and $/ \mathrm{s} /$ were selected with the expectancy that untrained probes $/ t, f, \mathcal{S}, t \mathcal{S} /$ would emerge since the feature bundles contained in $/ k /$ and $/ \mathrm{s} /$ combined, would provide training on all the sound 
features encompassed by the untrained phonemes. The results from training $/ \mathrm{k} /$ and $/ \mathrm{s} /$ showed generalization to the untrained sounds to varying degrees. Articulation testing revealed the emergence of the phonemes $/ f, t, t S /$; however, they were not always produced correctly and on $1 y$ a distortion of / $/$ was produced. This was considered an improvement over initial testing results in which the phonemes had been completely omitted. The authors concluded that direct training on $/ \mathrm{k} /$ and $/ \mathrm{s} /$ had led to a positive transfer to the untrained probes. They also pointed out that other omitted phonemes such as $/ n, h, w /$ which do not share similar features, had not emerged as a result of training (Ruder \& Bunce, 1981).

Similar results were obtained for the second subject, aged 4 years, in the Ruder and Bunce (1981) study. An inventory of this child's consonants consisted of $/ g, n, \eta, j /$. The following features were completely lacking: continuancy, (-) voicing, and stridency. Ruder and Bunce (1981) selected 2 training goals: (a) to establish labial consonants and (b) to teach features absent from the child's repertoire. The phonemes /b,k,s/ were chosen as training targets. Each phoneme was trained separately with articulation tests following each training period to assess changes in the child's sound system. Following training on /b/, the child was able to 
produce $/ \mathrm{m} /$. This addition was predicted since all the manner features of $/ \mathrm{m} /$ were already part of the child's feature system and training of /b/ provided the bilabial place feature (Ruder \& Bunce, 1981). The remaining two treatment targets $/ \mathrm{k} /$ and $/ \mathrm{s} /$ were selected to teach the features of (-) voicing and stridency. Following training on $/ k /$, the untrained phonemes $/ h, p, r /$ emerged; however, the expected phonemes $/ t /$ and $/ d /$, which share features with both the $/ \mathrm{k} /$ and $/ \mathrm{n} /$, did not emerge. It was not until completion of training the phoneme /s/ did the $/ t /$ and /d/ emerge. The reasons behind these results were not clear (Ruder \& Bunce, 1981). Although questions remain about generalization from trained to untrained sounds through sound feature analysis and target selection, Ruder and Bunce concluded that structuring articulation intervention to enhance generalization from trained to untrained sounds would be an efficient method to adopt.

In another study, Blache, Parsons, and Humphreys, (1981) explored the possibility of generalization from trained to untrained sounds within the same feature sound class. A minimal-word-pair matrix was used for teaching the linguistic significance of words differing by a single distinctive feature (e.g., pig/big). Seven subjects ranging in ages from 5 years 4 months to 6 years 
7 months were used in the study. Sound feature classes selected for training were based on the greatest number of errors presented by each subject. Two subjects received training on tense/lax $(p / b$ and $t S / d \xi)$, two on interrupted/continued ( $t / s$ and $S / t S)$, and one each on acute/grave $(f / \theta)$, mellow/strident $(\theta / s)$, and diffuse/compact $(s / \mathcal{S})$. It should be noted that the author's use of the terms tense/lax is not consistent with the definition developed by Chomsky and Halle (1968) who described both of the phonemes /tS/ and /d $3 /$ as tense sounds. Each subject participated in receptive/productive practice on three different minimal word pairs representing one target feature until $90 \%$ correct production had been attained. Posttesting results revealed a $73.3 \%$ reduction of feature errors by al1 7 subjects. This indicated a significant transfer of learning from trained to untrained sounds within the treated feature category. However, generalization had not occurred equally for all categories. The least amount of improvement (53.8\%) was noted in the feature category of continued/interrupted. In the other feature categories, strident/mellow, compact/diffuse, grave/acute and tense/1ax, an $82.2 \%$ improvement in feature errors was noted. In addition to improvement within the targeted feature categories, $30 \%$ of the errors in the untreated 
feature categories improved. Blache et al. (1981) attributed this to task generalization.

Generalization from trained to untrained sounds was also addressed in a study by Tyler et al. (1987). Their study was designed to assess the efficiency of two treatment approaches, namely a perceptionproduction/minimal pairs approach and a modification of the Hodson and Paden cycling approach. A secondary concern of their study was to test generalization from trained to untrained sounds taught in the context of the two approaches. Four children were used in this study. One of the children in the study (Subject A), aged 5 years 1 month, displayed the phonological process of gliding of fricatives. The phoneme / j/ was substituted for $/ s, z, \int, \theta /$, and the phoneme /w/ was substituted for $/ f /$ in the initial and medial positions of words. Sounds targeted in treatment were /f/ and /s/. Training consisted of a perception-production/minimal pairs approach. Probes of trained and untrained sounds in words were used to measure improvement. Posttreatment results indicated improvement from trained to untrained sounds within the sound class of fricatives. On the posttest, the target sounds /f/ and /s/ were produced with 100\% accuracy and the untrained sounds $/ z, J, \theta /$ were produced with $94 \%$ accuracy overall. 
Although the untrained sounds were reported as being 94\% correct in the final probe, caution for interpretation should be noted. Tyler et al. (1987) reported that / $/$ / was replaced by the fricative /s/, and / $\theta /$ was only inconsistently correct. Correct production was based on the child having acquired frication for a phoneme which had previously been produced as a glide. In addition, one of the untrained sounds / $/$ had actually been used as a treatment target in another part of the study.

Subject B, aged 3 years 8 months, used a total of nine deviant phonological processes at the onset of the study. The most prevalent deviant phonological process, stopping of fricatives, was selected as the target process for treatment. A11 of the sounds affected by this process were replaced by their homorganic stops $(e . g ., t / s, d / z, p / f, b / v, t / s, d / 3, t / \theta, d / z)$. The target sounds chosen for treatment were $/ \mathrm{s} /$ and $/ \mathrm{f} /$. The pretreatment probe indicated that stopping of fricatives in the initial position occurred with a frequency of $97 \%$. After 11 treatment sessions stopping of fricatives was reduced to a frequency occurrence of $26 \%$ overall with the trained sounds /s,f/ being produced with $83 \%$ accuracy and the untrained fricatives $/ z, v, \theta, S, y /$ being produced with $37 \%$ accuracy overa11. In the untrained sounds the 
greatest improvement (50\% accuracy) occurred with /z/ and IV/ which are the voiced cognates of the trained sounds $/ \mathrm{s} /$ and $/ \mathrm{f} /$.

The results of treatment for both subject $A$ and Subject B showed generalization of a feature from treated to untreated sounds within the same sound class. For subject $A$, this occurred with the process of gliding of fricatives, and for subject B, it occurred with stopping of fricatives.

A modified cycles approach to treatment was used with the other two children (Subject $C$ and subject $D$ ) in this study. The deviant phonological processes targeted for subject $c$, age 4 years 1 month, were the reduction of s-clusters and liquid clusters. The treatment targets chosen were /sn, $s p /$ and /fl, bl/ for each deviant process. The untreated clusters that were used as probes to determine generalization of treatment consisted of /sk, sw, st, sm/ and /p1, k1, g1, s1/.

The results from treatment showed that the targeted clusters /sn/ and /sp/ improved from 0\% accuracy to $75 \%$ accuracy and the untrained $s$-clusters improved from $3 \%$ to 47\% accuracy overall after two training cycles. The targeted 1 iquid cluster $/ f 1 /$ and /bl/ increased from $0 \%$ to $100 \%$ accuracy and the untrained liquid clusters improved from $0 \%$ to $94 \%$ accuracy overal1 by the fourth 
probe.

Subject D displayed several deviant phonological processes. Five different processes were targeted during the study. A clear estimate of generalization from treated to untreated target sounds could not be determined from the posttest results of this child's productions. Several sounds used as untreated sounds in the elimination of one deviant phonological process were then used as treatment targets in the remediation of another process.

Although the study conducted by Tyler et al. (1987) was designed mainly to compare the effects of two treatment approaches, the information provided about generalization from treated to untreated sounds within the same feature class or phonological process is valuable. In addition, Tyler et al. (1987) addressed the importance of considering a child's pretreatment phonological knowledge and sound feature repertoire when selecting the most efficient treatment target.

\section{Summary}

In all the studies cited above, there was a search for the most expedient and efficient means of identifying and remediating articulation/phonological disorders. Careful analyses of the sound systems or deviant patterns used by the subjects were made, and target sounds used to 
remediate the deviant processes efficiently were extrapolated. Ultimately their theories proved correct, that is, by training one or a few phonemes, several error sounds that share the same feature or features will spontaneously improve to various degrees. However, questions still remain. Why did some of the untreated sounds improve more than others? This investigator attempted to contribute to the discovery of some of the answers. In particular, is it possible to remediate one misarticulated strident phoneme and cause improvement to occur to other misarticulated strident phonemes? In addition, if this spontaneous improvement does occur, what part does voicing play? If the treatment target is a voiceless phoneme, will that generalize to the voiceless stridents to a greater degree than the voiced stridents? 


\section{CHAPTER III}

\section{METHODS}

Subject selection

The child selected for this single subject study was referred by a speech-language pathologist from the Vancouver School District $\# 37$. This child, aged 4 years 4 months, met the following criteria:

1. No known neurological, motor, or physical impairments that may effect speech production as subjectively determined through an interview with the parent about the child's developmental and health history, and assessment of oral-motor abilities.

2. $25 \%$ or less total occurrence of stridency in a 11 the strident phonemes tested, as evidenced through assessment using the Deep Test of Articulation (McDonald, 1964b) (see below).

3. No previous speech-language intervention targeting stridents in treatment.

4. Passing a bilateral pure-tone audiometric screening at $20 \mathrm{~dB} \mathrm{HL}$ for the frequencies of 500,1000 , 2000, and $4000 \mathrm{~Hz}$.

5. Demonstration of a receptive vocabulary no more 
than one standard deviation below the mean for the child's chronological age on the Peabody Picture Vocabulary-Revised (Form B) (Dunn \& Dunn, 1981).

Instrumentation

The Deep Test of Articulation (McDonald, 1964b) was used to elicit articulatory responses of the strident phonemes $(/ f, v, s, z, S, t S, d z /)$ and two phonemes from separate sound classes (i.e., /d,w/) in the releasing and arresting positions of words. The /3/ phoneme was not included in the study since it is not tested by The Deep Test, and therefore, would not be equally compared to the other strident phonemes. A total of 40 to 46 productions of each phoneme was assessed in various articulatory contexts according to the format of the test, with one exception. The phoneme / $\mathrm{w} /$ is only assessed by The Deep Test in the releasing position of words; hence, there were 22 rather than 46 examples.

This test required the child to make one compound word by combining two words represented by two separate pictures. For example, the child was presented with a picture of a tub and a picture of a sun. The two words were then to be pronounced as one word (i.e., tubsun). Responses were scored as correct if any strident was used. For example, if a strident other than the target strident was produced, it was considered correct because 
it possessed the underlying feature of stridency.

The Deep Test of Articulation is not a standardized articulation test. According to McDonald (1964a), testretest and split-half methods of determining reliability were not deemed appropriate for this test or any articulation test used with young children whose articulation is variable. McDonald (1964a) reported that the variety of phonetic contexts in which a sound is articulated should yield a representative sample of the child's ability to produce the sound being assessed.

Tests designed to obtain a similar sampling of the speaker's articulatory behavior should correlate strongly with the Deep Test of Articulation; however, at the date of the publication of the test, only one study had been conducted. Whetstone (as cited in McDonald, 1964a), created four different picture deep tests modelled after the principles of the Deep Test of Articulation and administered them to 30-43 children. The Pearson Product Moment correlations obtained for the various pairings of the four forms showed a range from .60 to .97 . McDonald (1964a) briefly addressed validity. In his opinion, the test is valid insofar that it measures a child's ability to produce the sound being tested in the context being tested. 


\section{Procedures}

\section{Treatment Target Selection}

One strident phoneme (i.e., /s/) from the pretested stridents was selected as the treatment target. The remaining strident phonemes were regarded as untreated control sounds (control group \#1) to determine whether generalization would occur from treated to untreated sounds within the same sound class. Two other misarticulated phonemes from separate and distinct sound classes (i.e., /d/ and /w/) were selected as control sounds (control group \#2). Group \#2 was used to assess across-feature class generalization of treatment. Reliability

Pretest and posttest responses were recorded on a Sony PCM-2300 DAT recorder with an Audio-technica Atm 31a condenser microphone. Additionally, the examiner transcribed on-line all of the child's responses of the target sounds being tested. An independent observer from the graduate program in Speech and Hearing Sciences also transcribed on-line the responses from the pretest and posttest. She sat behind and slightly to the side of the examiner in a position that prohibited viewing of the examiner's recording sheet. Transcriptions were compared between the examiner and observer. Any discrepancies in judgement between the examiner and observer were 
reevaluated using the auditory recording from the DAT. Only fully resolved transcriptions were used in the analysis samples. This method is consistent with methods used in other studies (Blache et a1., 1981; Dinnsen, Chin, Elbert, \& Powe 11, 1990). A 97\% agreement rate between the examiner and observer was achieved on the pre- and posttests combined, which meant that a total of 24 responses were not used in the final analyses.

\section{Treatment Protocol}

Treatment sessions took place over an 8-week period for a total of 24 sessions of 50 minutes each, at the child's daycare center. The treatment protocol used was based on Hodson and Paden's (1991) approach to remediation of phonological disorders. The design adopted the perception, production-practice, and home program activities outlined by Hodson and Paden (1991). However, rather than cycling through several error sounds or deviant processes as is standard with the Hodson and Paden (1991) approach, only the target sound was taught in various contexts. For example, the treatment target phoneme /s/ was taught in the final position of words in a /ts/ blend in the first session. During the second session it was taught in words in the final/ps/ blend and so on.

Word selection. The target sound was taught in 
blends in the initial and final positions of monosyllabic words (see Appendix A). In the initial sessions, the examiner presented the target sound in a different position or with a different blend each session. For example, in session one, the target sound was trained in a blend in the final position of words (e.g., cats, hats); in session two, the target sound was trained in a different blend in the final position (e.g., tops, caps) and so on. In later sessions, a combination of previously targeted word positions or consonant blends were used. The word position or blend in which the target phoneme was taught depended on the child's abilities and performance during the course of the study. For example, as the child became more proficient in the production of initial and final/s/ blends, the two word positions were targeted during the same sessions.

Production practice words used in treatment were carefully selected to be age appropriate and to exclude a 11 non-targeted stridents and the two untreated sounds from control group \#2. Only the target strident was modelled and shaped to obtain correct productions. Other sounds in the training words were not corrected if produced in error.

At the end of each session, probes for next session's production-practice words were made immediately 
preceding the second auditory bombardment activity (see below). The child was asked to repeat words from a list of potential production-practice words into the microphone of the auditory trainer or electronic amplification system as he listened through the earphones. These words were preselected by the examiner to contain the target sound in the word position or consonant blend being trained. From this probe 2 to 20 words were chosen to be used in the activities and games during the sessions.

Perception Practice. Each session began and ended with a period of auditory bombardment. During this activity, the child listened to the investigator as she read 12 to 15 words containing the target phoneme in the word position or consonant blend being taught that day. The examiner read the words into an auditory trainer or electronic amplification device as the child listened through earphones. This perception activity is designed to heighten the awareness of the training sound by giving the child the opportunity to hear the target sound in several words at a slightly amplified level.

Production Practice. Picture cards were made for each production-practice word. Line drawings or pictures of the selected words were provided along with $5 \times 8$ inch index cards. The child had the opportunity to glue the 
pictures onto the index cards and color them if so desired. The words corresponding to the pictures were written on the cards by the examiner. The word cards were then used in various activities and games that required the child to say the words several times. The goal of each session was to obtain as many correct productions of the target sound in words as possible. The examiner used modelling, shaping, and cuing techniques (i.e., tactile and visual cues) when necessary, to obtain correct productions. Social reinforcement and a token system of reinforcement were used.

Home Program. The home program suggested by Hodson and Paden (1991) was also employed in this study. Each session's word cards and the listening list were sent home with the child on weekends, and during the week, they remained at the daycare center. It was requested that the parent or daycare provider read the words from the listening list to the child and then asked the child to name the picture cards once a day. A home folder was created that provided a means for recording daily practices. Upon completion of each home practice activity, a sticker star was placed in a square for that day. After five stars had been obtained, a larger sticker was earned. 


\section{Probes}

Probes to assess improvement of the target sound in untreated words were administered prior to the auditory bombardment activity at the beginning of every other treatment session beginning after the fourth treatment session (see Appendix B). The probes were administered for two reasons: (a) to assess generalization of the target phoneme /s/ from treated to untreated words during the course of the study, and (b) in the event that the child had reached a criterion of $90 \%$ or $18 / 20$ correct productions over two consecutive sessions, treatment would have been terminated prior to the session \#24 and the posttest would have been administered at that time. This, however, did not occur; therefore, training continued to the 24 th session.

Probes were in the form of a single-word elicited production task using pictures. Twenty picture stimuli were presented to the child with a prompt to tell the examiner what is in the picture. If the child did not respond or responded with another word, the investigator told the child the word and placed that card at the bottom of the pile for presentation at a later point, or the card was replaced with another probe word that contained the target sound in the same word position. Most probe words contained the singleton /s/ in the 
initial position of words. These types of words were chosen because most of the correct productions of /s/ on the pretest were in the arresting (final) position of compound words. Hence, a more accurate display of carryover from treated to untreated words would be determined by probes containing the /s/ in the initial position of words. No feedback was provided during the probes. The same picture cards were presented in randomized order during each probe. This procedure is in accordance with other similar studies (Powell, Elbert, \& Dinnsen, 1991; Tyler et a1., 1987).

A total of 27 probe words were used during the study, although on 1 y 20 were used in each session's probe. The extra 7 cards were used as replacements for the picture cards the child failed to name. None of the probe words were used during the treatment sessions.

Data Analysis

At the conclusion of the treatment sessions, the Deep Test of Articulation was readministered as a posttest. The procedure was the same as described above for the pretest. The treatment target, the strident sounds in control group \#1, and the sounds in control group \#2 were assessed in the releasing and arresting positions of words in accordance with the test protocol. Pre- and Posttest Comparison 
Results from the pretest and posttest were compared in three ways. First, the change in the use of stridency in the production of the treated strident /s/ and the untreated strident phonemes $(/ z, v, f, S, t S, d z /)$ was analyzed. In addition, the change in the accuracy of production of the untreated non-strident phonemes /d/ and /w/ (control group \#2) was determined. Second, the untreated strident phonemes were divided into two groups: the voiced stridents ( $i . e ., / v, z, d z /$ ) and the voiceless stridents $(i . e ., / f, S, t S /$ ). Because the treatment target was a voiceless strident $(i . e ., / s /)$, it was of interest to this study to analyze whether there was a variance in the post treatment results between the two groups (voiced and voiceless) of untreated strident phonemes. Finally, in addition to the assessment of generalization of stridency from treated to untreated stridents, the improvement or change in the use of stridency for each individual untrained strident was descriptively analyzed.

The percent of correct productions was calculated by dividing the total number of correct productions by the total number of test items for each sound and multiplying the quotient by 100 . The percent of change was calculated by dividing the difference between the pretest and posttest percentages by the percent of incorrect productions (i.e., the potential trials available for 
improvement) on the pretest. For example, a phoneme produced with 50\% accuracy on a pretest has a $50 \%$ potential for improvement. If on the posttest the phoneme is produced with $60 \%$ accuracy the percent of change is $20 \%$ (e.g., $60 \%$ posttest $-50 \%$ pretest $=10 \%$ difference $\div 50 \%$ potential for change $=20 \%$ increase in correct productions). 
CHAPTER IV

RESULTS AND DISCUSSION

Results

The purpose of this single subject study was to determine whether the treatment of one misarticulated strident phoneme would lead to improved articulatory performance of other untreated misarticulated strident phonemes. In addition, two sounds from separate and distinct sound classes (i.e., /d/ and /w/) were selected as control sounds to assess across-feature generalization from treated to untreated sounds. A secondary purpose of this study was to compare the difference in response performance between voiced and voiceless untreated strident phonemes.

The Deep Test of Articulation (McDonald, 1964b) was used to assess al1 phonemes for the pre- and posttests. This test assesses a 11 phonemes as singletons in the releasing and arresting positions of words that are combined to form one compound word (e.g., tub + sun $=$ tubsun). A percent of correct production for the tested phonemes was calculated by dividing the number of correct 
productions by the total number of contexts tested, then multiplying by 100 .

The subject who participated in this study was a 4year 4-month-old male whose pretreatment performance on The Deep Test displayed $25 \%$ overall accuracy on a 11 strident phonemes tested ( $i . e ., / s, z, f, v, S, d z, t S /$ ) tested. The overall pretreatment performance on the nonstrident control sounds was $52 \%$ for $/ d /$ and $0 \%$ for $/ w /$. The subject was trained on the strident $/ \mathrm{s} /$ in blends in the initial and final positions of words. A total of 24 treatment sessions of 50 minutes each were completed.

\section{Results for All Sounds}

The treated strident /s/ was produced with $52 \%$ accuracy on the pretest (i.e., $24 / 46=.52 \times 100=52 \%$ ) and $56 \%$ accuracy on the posttest (i.e., $25 / 45=.56 \times 100$ $=56 \%)$. This is an $8 \%$ increase in correct productions for the treated strident /s/ as measured by The Deep Test. The percent of increase in correct productions (i.e., 8\%) was calculated by subtracting the percent of correct productions on the pretest from the percent of correct productions on the posttest $(56 \%-52 \%=4 \%)$ and dividing the result by the potential for change $(4 \% \div 48 \%$ $=8 \%$ increase in correct productions).

Nearly all correct /s/ productions were noted in the arresting positions of compound words (e.g., housepipe) 
on both the pretest and posttest. Only once was /s/ produced correctiy in the releasing position (i.e., tubsun).

Results from The Deep Test for the untreated stridents, as a group, indicated a $51 \%$ increase of stridency production (Figure 1). Again, the percent of increase in correct productions (i.e., 51\%) was calculated by subtracting the percent of correct productions on the pretest from the percent of correct productions on the posttest $(61 \%-21 \%=40 \%)$ and dividing the result by the potential for change $(40 \% \div$ $79 \%=51 \%$ increase in correct productions). This change in correct stridency production for the untreated stridents indicates a considerable increase. A notation regarding these results must be mentioned here. If the child did not produce the exact target strident, but substituted another strident for the target strident, it was scored as correct on both the pretest and posttest. This method was chosen since the primary question of this thesis was whether generalization of stridency from treated to untreated stridents would indeed occur. Four of the six untreated stridents were occasionally substituted for other stridents. 


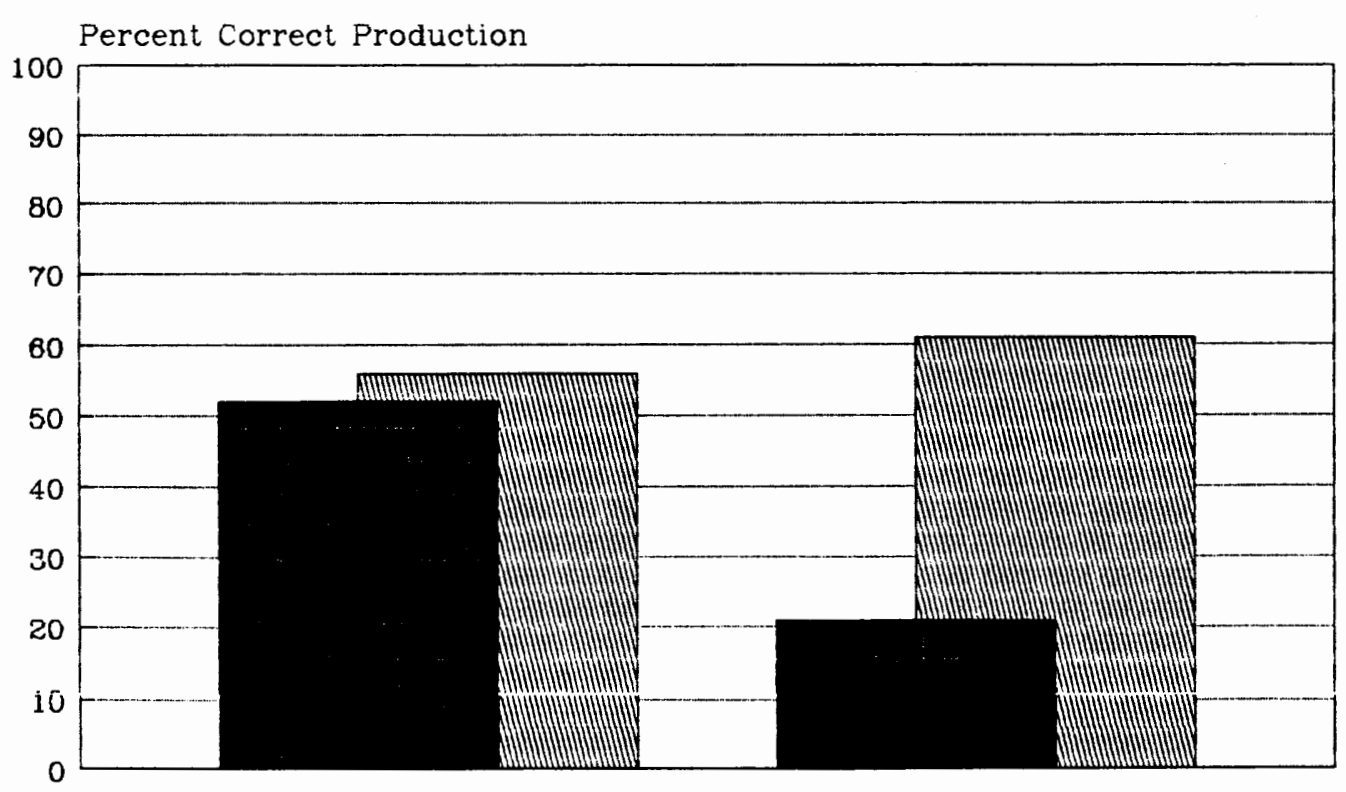

Treated strident

Untreated stridents

Treated vs. Untreated Stridents

Pretest Dostion Post

Figure 1. Percent of correct production of treated and untreated stridents.

The phoneme /f/ was consistently substituted for $/ S /$ (e.g., fiflfish), /ts/ was often substituted for /dz/ and $/$ tS/ (e.g., tsair/chair; tsar/jar), and /s/ was substituted for $/ z /$ twice. In all of these examples, the replacement sounds were stridents or included a strident as is the case with /ts/.

Results from the pre- and posttests for the untreated non-stridents $/ d /$ and $/ w /$ are shown below (see Figure 2). No change was noted with the phoneme /d/. It was produced with $52 \%$ accuracy on both the pre- and 
posttests. The phoneme /w/ increased from $0 \%$ accuracy on the pretest to $100 \%$ on the posttest. Both phonemes are early developing phonemes with /w/ generally being mastered by 3 years of age and /d/ by 4 years (Sander, 1972 )

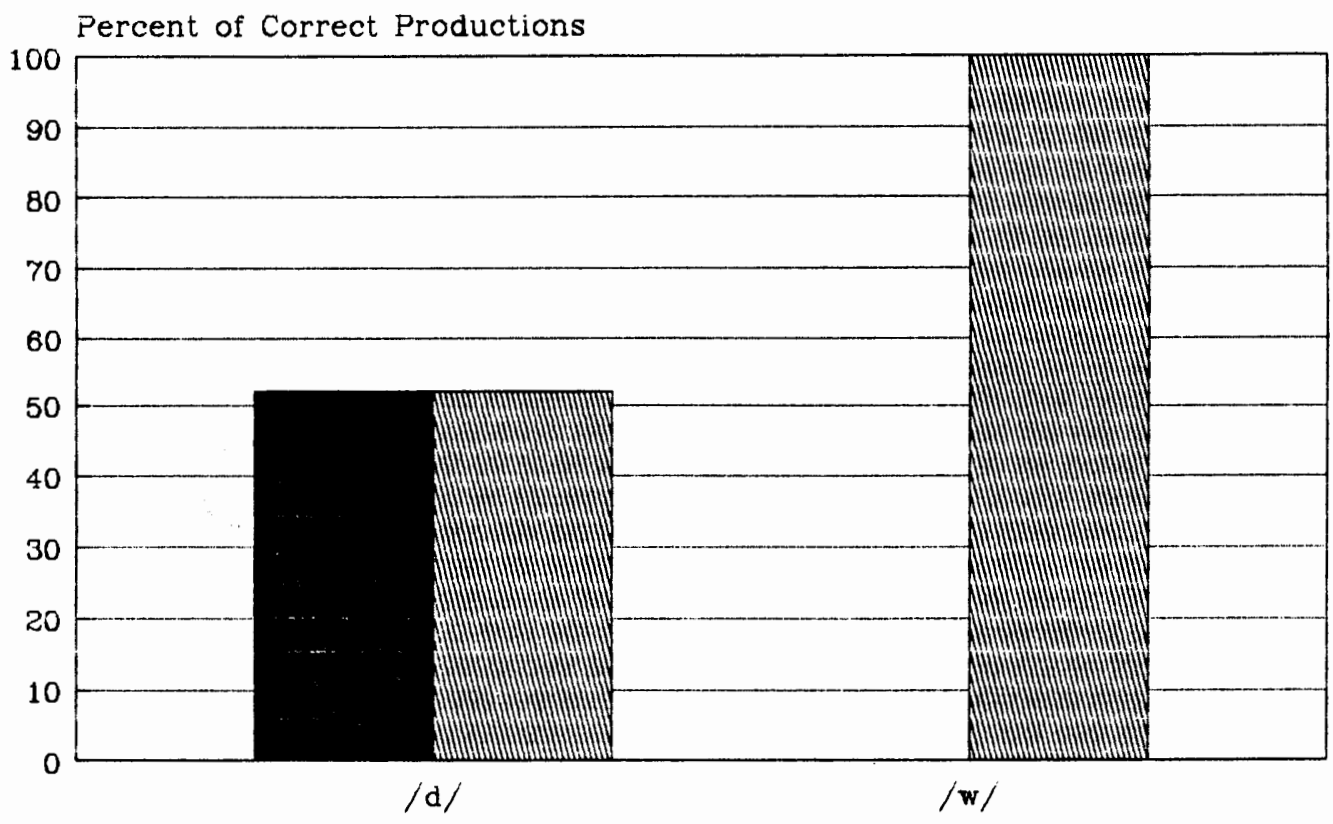

Non-strident Control Sounds

Pretest AllmW Posttest

Figure 2. Percent of correct responses of non-stridents.

In summary, overall production of the untreated stridents improved considerably; the treated strident /s/ improved only 8\%. One of the non-strident control sounds (i.e., /w/) improved significantly, and no change was seen in the other control sound ( $i . e ., / d /)$. 
Voiced and Voiceless stridents

A secondary purpose of this study was to analyze the generalization from treated to untreated strident phonemes with regard to voicing. The results from testing indicated improved production for both the untreated voiceless $(/ f, S, t S /)$ and voiced $(/ z, v, d \xi /)$ strident phonemes (see Figure 3 ). Greater improvement occurred with the voiced (vo) strident phonemes.

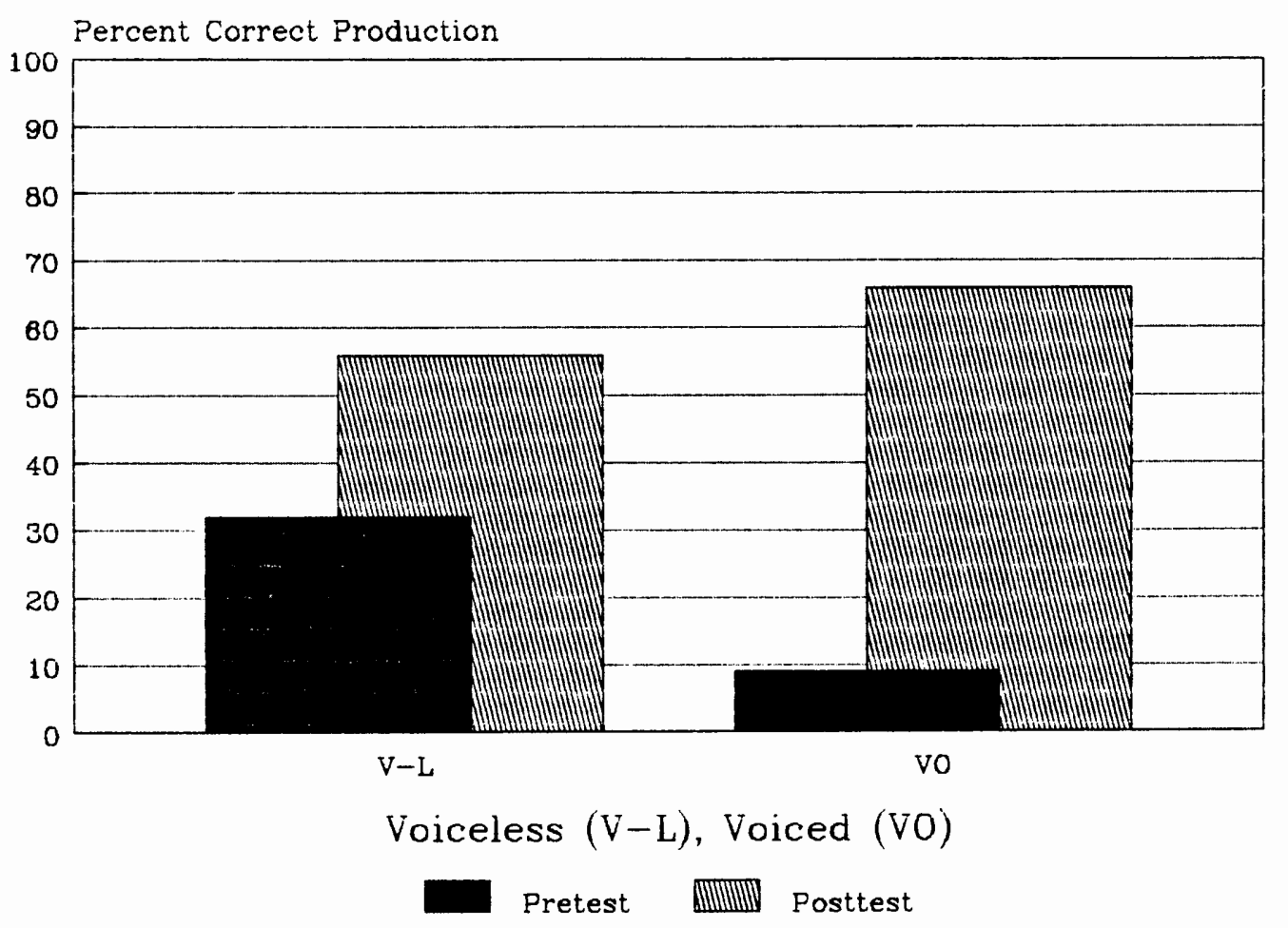

Figure 3. The percent of correct productions of the untreated voiceless and voiced strident phonemes.

There was a $63 \%$ increase in correct productions for the voiced (VO) stridents whereas production of the voiceless 
$(V-L)$ stridents improved $35 \%$. These results are interesting since more improvement occurred to the voiced stridents as a group and the treatment target for this study was the voiceless strident /s/.

Overal1, the results from the pretest and posttest indicated that a greater increase in correct stridency production occurred to the voiced stridents than to the voiceless stridents. In addition, as was noted above with the treated strident $/ s /$, the correct productions predominantly occurred in the arresting positions of the compound words.

\section{Individual sound Changes}

Table 1 shows the percent of correct productions of a11 of the tested sounds on the pretest and posttest. In addition, the percent of change was calculated for each phoneme in the same manner as was described on page 37.

Little change was seen with the treated strident /s/. There was an increase from $52 \%$ to $56 \%$ correct productions which is only an $8 \%$ change from pretest to posttest. No change was seen with the untreated strident $/ S /$ ( $0 \%$ change) and the non-strident control /d/ (ox change). In contrast, some change occurred to the phoneme $/ f /$ ( $23 \%$ change), and considerable changes were noted in the strident phonemes /tS/ ( $56 \%$ change), $/ z /(50 \%$ change), /v/ ( $97 \%$ change), /dz/ ( $100 \%$ change), 
and the non-strident /w/ (100\% change).

Table 1

Percent of Correct Productions of the Individual Treated and Untreated Phonemes

Phoneme Pretreatment Posttreatment $\begin{gathered}\% \text { of } \\ \text { Change }\end{gathered}$

Treated strident
/s/
$52 \%$
$56 \%$
$8 \%$

Untreated stridents

$\begin{array}{lrrrr}/ f / & 48 \% & 60 \% & 23 \% \\ / S / S / & 50 \% * & 52 \% & 4 \% \\ / \mathrm{t} / & 0 \% & 56 \% * & 56 \% \\ / \mathrm{z} / & 4 \% & 52 \% & 50 \% \\ / \mathrm{V} / & 23 \% & 98 \% & 97 \% \\ / \mathrm{d} / & 0 \% & 52 \% & * & 100 \%\end{array}$

Untreated controls
/d/
|w/
$52 \%$
$52 \%$
$100 \%$
$100 \%$

Note. The asterisks $(*)$ indicate the following

substitutions: /f/ was consistently substituted for the target phoneme $/ S /$, the sequence /ts/ was generally substituted for $/ t S /$ and $/ d z /$, and the voiceless cognate /s/ was substituted for /z/ twice.

In summary, little or no change occurred to the treated strident $/ \mathrm{s} /$, the untreated strident $/ S /$ and the untreated non-strident /d/. Considerable improvement 
was noted in the untreated stridents / $f, t \mathcal{J}, z, v, d j /$ and the untreated non-strident $/ \mathrm{w} /$. Correct productions did not decrease for any of the sounds studied.

\section{Probe}

A probe was administered every other treatment session beginning after the fourth session. This activity required the child to name 20 picture cards presented in random order. The probe was used to assess generalization of the target sound from treated to untreated words during the course of the study and to establish a criterion (90\% correct productions over two consecutive sessions) for possible termination of treatment sessions. This terminal level was not achieved. The results of the probes are shown in Figure 4. The child attained $85 \%$ correct productions on four probes $(8 / 1,8 / 5,8 / 23$, and $8 / 30)$.

The fewest correct /s/ productions in untreated words occurred on $7 / 22,7 / 26$, and $8 / 9$. The first two probes showed relatively few correct responses which would be expected since they were presented early in the treatment period. The drop in correct productions on $8 / 9$ was unexpected since the previous two probes showed 85\% correct responses and the following probes showed $65 \%$ or better in correct responses. 


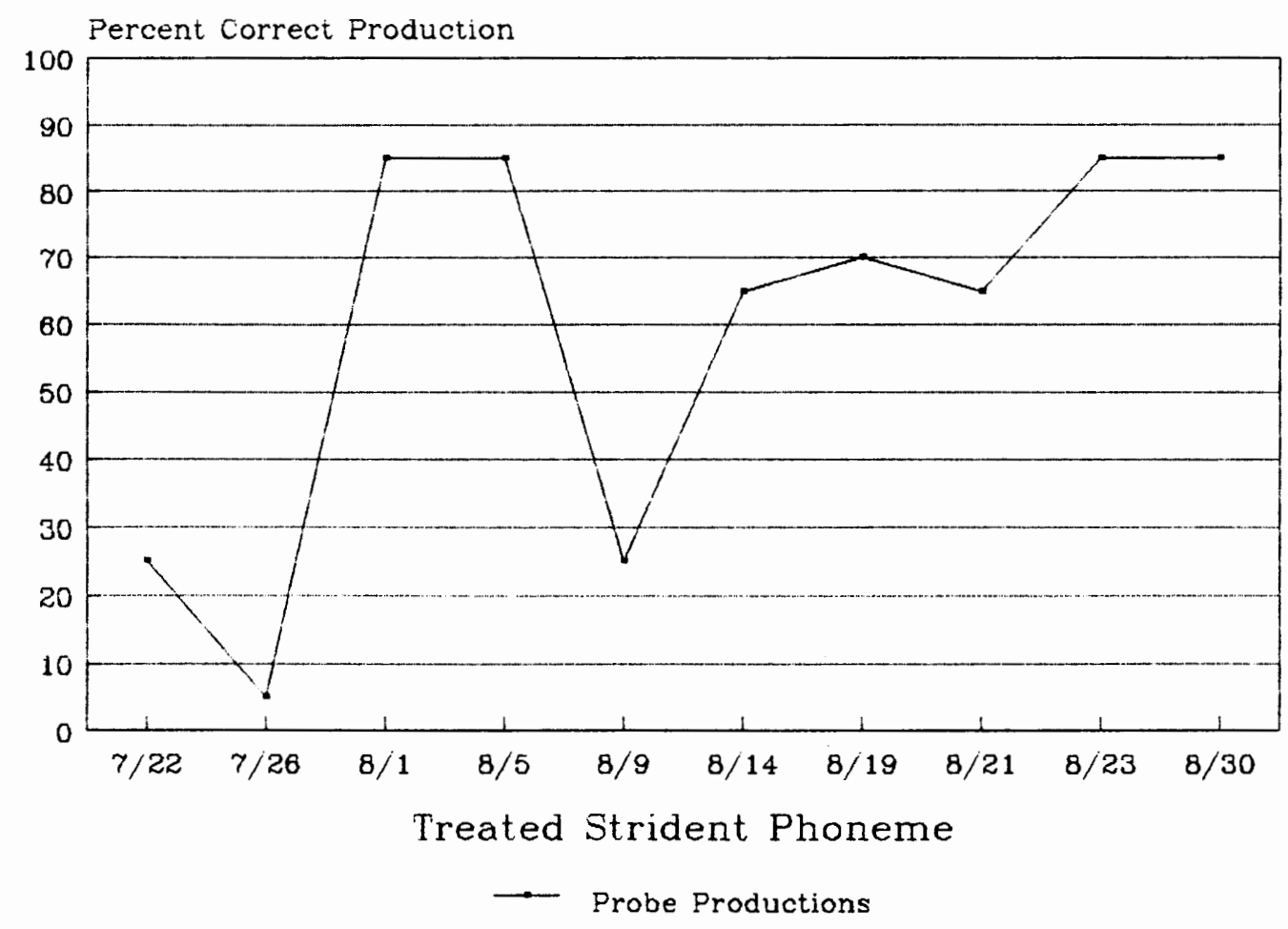

Figure 4. Percent of correct productions of /s/ in untreated words from July through August.

Throughout the study, an increase in correct productions was seen in untreated words. For this child, generalization occurred from treated to untreated probe words to a greater degree than what was displayed on The Deep Test.

\section{Discussion}

\section{Generalization of Stridency}

Overall, generalization did occur to the untreated strident phonemes. As a group, they improved from a pretreatment accuracy of $21 \%$ to a posttreatment accuracy 
of $61 \%$. This $51 \%$ increase is considerable and indicates a positive transfer of learning from the treated /s/ to untreated stridents. These results support the findings of other studies.

McReynolds and Bennett (1972) trained one child on the phoneme /f/ to teach the underlying feature of stridency. The untreated stridents improved significantly. In fact, the untreated strident /s/ was produced with 100\% accuracy on the posttest. Two other subjects from that same study were trained on (+) continuancy and (+) voicing. Again, the untreated phonemes sharing these underlying features improved spontaneous ly.

Costel10 and Onstine (1976) supported the findings of McReynolds and Bennett (1972) when they taught the underlying feature of (t) continuancy to two children by targeting the phonemes $/ \theta /$ and $/ s /$. The combined results showed that the untreated continuants /S, $z, \gamma /$ were produced with $80 \%, 90 \%$, and $48.5 \%$ accuracy, respectively, on the posttest. In 1981, Ruder and Bunce conducted a study for the purpose of treating more than one underlying feature. One of their subjects had a very 1 imited sound repertoire which consisted of $/ \mathrm{m}, \mathrm{b}, \mathrm{g} /$ and some vowels. It was determined that the following feature bundle was lacking: continuancy, stridency, 
coronal, (-) voicing, and high. Two targets $(/ \mathrm{k} /$ and /s/) were chosen for training. The posttest results showed emergence of four untreated phonemes $(/ t, f, S, t S /)$ that shared some or all of the underlying features. Phonemes from separate feature bundles $(/ n, h$, w/) that were lacking from the child's sound system did not emerge.

Similarly, Tyler et a1. (1987) showed a reduction of the deviant processes of gliding and stopping of fricatives with two children. Blache et al. (1981) treated several feature errors in 7 different subjects. Results were variable, but, in general, positive changes occurred.

In all the studies cited above, the percent of improvement to treated and untreated sounds was deemed clinically significant. Some sounds were as much as $100 \%$ accurate on the posttests. The percent of improvement to untreated sounds in this study is not quite as large; however, the results do show a positive transfer of learning.

\section{The Treated Phoneme /s/}

The relative lack of change to the treated phoneme /s/ displayed by the subject who participated in this study does not compare favorably to the results of other studies. Only a $4 \%$ increase in accuracy (percentage of 
change $=8 \%$ ) was attained on The Deep Test. In the studies cited in the Literature Review section, the treated phoneme(s) increased in accuracy to a much greater degree. The lowest posttest accuracy was $73 \%$ the highest was 100\% (B1ache et a1., 1981; Coste110 \& Onstine, 1976; McReynolds \& Bennett, 1972; Ruder \& Bunce, 1981; Tyler et a1., 1987).

Two possible reasons for this have been explored by the investigator: (a) the remediation program used during the treatment sessions and (b) the test used for pre- and posttesting. The phonological cycling approach (Hodson \& Paden, 1991) was modified to suit the study. Hodson and Paden (1991) suggested that each target pattern be treated for 2 to 6 hours a cycle and then later be recycled after treating other target patterns. This allows the child to internalize and experiment with a new articulatory pattern. Through their research, they have discovered this to be typical behavior in normal developing children. In this study only the /s/ was targeted and a posttest was administered immediately following the 24 sessions. This may not have allowed the child time to internalize and experiment with a newly learned pattern. In addition, the phoneme /s/ was trained in blends, but tested in singletons on The Deep Test; hence, this may indicate the need to train in the 
context of singletons as wel1 as blends.

The other possible reason for the lack of a greater increase in accurate productions of the treatment target on the posttest may have been influenced by the procedure and format of The Deep Test. The child in this study was required to produce approximately 46 examples of each of the $9(/ s, z, f, v, t S, d z, S, d /)$ tested phonemes except for $/ w /$ which was only tested in the releasing position. This required approximately 390 productions. It is the opinion of the investigator that this was too much to ask from this highly unintelligible child. The child appeared frustrated and hesitant to say words or sounds over and over that were incorrectly produced. At times, the child would say he did not know the name of something he had named previously or he refused to say anything. The Deep Test became a very laborious and frustrating experience. It was felt that the child did not give his best performance.

In contrast to the minimal change shown on The Deep Test for the treated strident $/ \mathrm{s} /$, the probes showed a greater change in untreated words. Perhaps the reason for this lies in the format used to test generalization to untreated words. Al1 the probe words were presented in the same format as the production-practice words used in treatment. It is possible that the child was 
generalizing the production of /s/ more to similar stimuli than to different formats such as The Deep Test. This rationale is supported by examples from the treatment sessions. The child was taught to name the production-practice cards and also to recognize the /s/ in each of the treatment words. The child rarely produced the treatment words incorrectly when asked to name the pictures. However, when the real objects were used in an activity (e.g., a dog named spot or a snajl from the aquarium), the correct production was not produced spontaneously and prompts had to be reintroduced. The picture cards used for the probes, not only looked the same as the production-practice cards, but also had the words written on them. This similarity in format may have stimulated a higher percentage of correct responses on the probes.

Untreated Control Sounds

The results from the posttest for each of the control sounds (i.e., /d/ and /w/) was varied. The phoneme /d/ did not change, but the /w/ improved $100 \%$. In the study by Blache et al. (1981), similar findings were noted, that is, one third of the untreated feature substitutions improved. They attributed this to task generalization. This perhaps is the case since it is logical that, while children become more aware of their 
sound productions through treatment, a conscious effort to change a deviant speech pattern may occur.

creaghead et a1. (1989) cited several cross-

sectional studies that presented the general sequence and ages at which consonants are acquired in meaningful words by children. In most of the studies, /w/ was produced correctly at an earlier age than /d/. However, both sounds are mastered at least by age 5 , and generally by ages $31 / 2$ to 4 years. In most of the studies cited in the Literature Review section of this thesis, the $/ \theta /$ was used as the untreated control sound. This is one of the later developing sounds. In fact, some studies have shown that it may take up to age 7 to master (Creaghead et al., 1989). This may have been why no change was seen with the $/ \theta /$ control sound in other studies, whereas in this study, earlier developing sounds were used as the untreated control sounds.

\section{Untreated Strident Changes}

The overall change to the voiced untreated stridents was greater than to the voiceless untreated stridents (see figure 3 ). This was not predicted since the treatment target was a voiceless strident. However, in the study conducted by Tyler et al. (1987), similar results occurred with one subject who was treated for stopping of fricatives. Although the treatment targets 
$(/ \mathrm{s}, \mathrm{f} /)$ were voiceless sounds, a greater increase of correct productions was noted with the untreated voiced cognates $(/ z, v /)$ than with the other untreated sounds $(/ S, \theta, \gamma /)$. In contrast, the opposite occurred in the study by McReynolds and Bennett (1972). One subject was trained on $/ \mathrm{f} /$, another subject was trained on $/ \mathcal{S} /$. For both subjects, greater improvement was noted in the untreated voiceless sounds than in the untreated voiced sounds.

Hodson and Paden's (1991) discussion of the selection of treatment targets is relevant here. In the case of treating final consonant deletion, they recommended training voiceless obstruents, but not voiced obstruents. According to their observations, the voiced cognates of the target sounds emerged spontaneously without intervention (Hodson \& Paden, 1991).

The dichotomy of the results presented above indicate a need for further investigation. Without completely analyzing a child's sound system and inventory of underlying features, it is difficult to determine why certain changes occur while others do not.

\section{Individual sound Changes}

Each individual strident was tested in the releasing and arresting positions of words on The Deep Test. The arresting position was tested by combining two words. 
For example, the two words house + pipe would be produced as one word (i.e., housepipe) with the strident /s/ being tested in the arresting position of a syllable when combined into one word. The releasing position was tested in a similar manner; hence, the target phoneme was produced in a position that released a word (e.g., pipesun). An analysis of the results between the pretest and the posttest with regards to the releasing and arresting positions revealed some dramatic results. For a 11 the untreated strident phonemes (i.e., /f, S, tS, z,dz/) except for $/ \mathrm{V} /$, the greatest change occurred in the arresting position of words. A comparison of the pretest and posttest results showed a $100 \%$ increase in stridency production (i.e., pretest $=38 \%$ stridency; posttest $=$ 100\% stridency) in the arresting position of words. In the releasing position of words only a $4 \%$ increase of stridency occurred (i.e., pretest $=0 \%$ stridency; posttest $=4 \%$ stridency). In contrast, the phoneme $/ \mathrm{V} /$ improved nearly equally in the releasing and arresting positions. These results strongly indicate that this child acquired stridency production in the arresting position with more ease than in the releasing position of words. McReynolds and Bennett (1972) commented on this issue briefly. They also used The Deep Test as the preand posttest for their study. For some untreated sounds, 
greater improvement occurred in the releasing position, however, others showed it in the arresting position.

An analysis of the types of errors and changes made from the pretest to the posttest for the individual untreated stridents is of interest. The phoneme / $/$ / had been produced either as a /b/ (i.e., process of stopping) or it was completely omitted on the pretest. On the posttest, /V/ was produced with $98 \%$ accuracy. The phoneme $/ z /$ was omitted $96 \%$ of the time on the pretest. On the posttest, /z/ or the cognate /s/, was used in $52 \%$ of the tested contexts.

In the releasing position, the phonemes /d $/$ and /t $S /$ changed from being produced as glides (i.e., yair/chair) on the pretest, to either being omitted (i.e., _ar/jar) or produced as a voiced stop (i.e., dair/chair) on the posttest. In the arresting position, both phonemes were omitted on the pretest and produced as /ts/ (i.e., tsair/chair) on the posttest.

The phonemes /f/ and /S/ showed the least amount of change from the pretest to the posttest. In the releasing position of words, the process of stopping and sometimes voicing was applied to the phoneme /f/ (e.g., pork or bork replaced fork) on both tests. In the arresting position, /f/ was used correctly in most contexts. The phoneme / $/$ / was omitted in the releasing 
position and substituted by / $f /$ in the arresting position on both the pretest and posttest.

The results from this study and those cited above in the Literature Review section are inconclusive. The issue of voicing, word position, and the types of changes that occur, should be explored further.

\section{Summary}

The research question asked was: Would training one misarticulated strident phoneme lead to the improvement of other misarticulated strident phonemes? Also, would other misarticulated untreated sounds from separate and distinct sound classes change? In addition, what changes would occur to the voiced and voiceless stridents?

This study and others cited previously have shown that generalization from treated to untreated sounds within the same feature class did occur to varying degrees for the subjects used in these studies. In addition, a transfer of learning occurred from trained words or nonsense syllables (McReynolds \& Bennett, 1972) to words on The Deep Test and probe words.

In most of the studies cited in the Literature Review section, control sounds from separate and distinct sound classes did not change (Costello \& Onstine, 1976; McReynolds \& Bennett, 1972; Ruder \& Bunce, 1981; and Tyler et al., 1987). However, in this study and the 
study by Blache et a1. (1981) sounds from separate feature classes did improve. This could be attributed to task generalization or the natural course of sound acquisition. The reasons behind these differences are on ly speculative.

The issue of generalization to untreated sounds with regard to voicing is inconclusive. In this study and the study by Tyler et a1. (1987), greater improvement occurred to the untreated voiced sounds, even though the treatment targets were voiceless. The study by McReynolds and Bennett (1972) produced opposite results. Dramatic differences were seen when an analysis of the sound changes with regards to the releasing and arresting positions of words/syllables was made. Nearly al1 of the correct strident productions occurred in the arresting ( $f$ inal) position rather than in the releasing (initial) position of words. 


\section{CHAPTER V \\ SUMMARY AND IMPLICATIONS}

\section{Summary}

This single-subject study was developed to investigate the potential of treating one misarticulated strident phoneme to induce generalization to other misarticulated strident phonemes. One male, aged 4 years 4 months, was trained on /s/ in words. A treatment program, modified from the Hodson and Paden (1991) phonological cycling approach, was used. Two untreated sounds from separate and distinct sound classes were used as control sounds to monitor across-feature class change. A total of 24 treatment sessions of 50 minutes each were provided.

The results from the pretest and posttest showed an increase of $51 \%$ correct stridency production for a 11 untreated stridents and an $8 \%$ increase for the treated /s/. Results of probe measurements showed $85 \%$ correct productions of /s/ in untreated words on several occasions. The change in the untreated control sounds was varied. One phoneme showed no change; another improved 100\%. A positive transfer of learning from 
treated to untreated stridents was exhibited by this subject.

\section{Implications}

\section{Clinical Implications}

The outcome as well as the procedures of this study provide some valuable considerations for a clinician. The outcome from training one strident showed favorable results for generalization to other phonemes sharing the feature of stridency, particularly in the arresting position of words. For this subject, the arresting position appeared to be an easier position for producing newly acquired sounds. Therefore, perhaps training should have emphasized the releasing position of words more than it did. Another possibility of why this occurred may have been that the child was displaying the deviant phonological process of initial consonant deletion. Since a complete phonological analysis was not conducted initially, it is difficult to say if this was the case.

The issue of voicing must also be considered. This subject displayed confusion for the use of voiceless versus voiced sounds. For example, both / $/ \mathrm{p} /$ and $/ \mathrm{b} /$ were substituted for $/ \mathrm{f} /$. Again, since a complete phonological analysis had not been performed initially, it is unclear if voicing was a deviant phonological 
process being displayed by this subject.

For the practicing clinician, a complete analysis of errors and deviant patterns being displayed would be very beneficial for selecting treatment targets. In addition, probes that evaluate changes that occur as treatment progresses would be worthwhile. As children acquire new sounds, they explore and internalize various features according to their own understanding and capability. This may not always coincide with the end result desired by the clinician; therefore, changes in the treatment program may be needed as learning occurs.

The training program used in this study was appropriate for training a new sound to this child. The picture cards used in the various activities as well as for practice at home provided a cohesive and manageable program. However, as was mentioned earlier, the correct use of /s/ did not readily transfer to real world objects such as a snail in the aquarium. This observation must be addressed in any intervention program. Generalization may occur to similar stimuli but not to objects or other situations.

As an assessment tool, The Deep Test would not be recommended for use in the clinical setting for a child with multiple sound errors. It does not provide information about deviant phonological processes which 
can be invaluable information when working with a highly unintelligible child. Also, the time needed to administer the test is prohibitive. The Deep Test would be useful to establish the contexts in which a sound would need to be targeted for a person with a few sound errors.

In summary, it can be assumed with some confidence, that generalization will occur from treated sounds to untreated sounds sharing the same features. However, other types of errors or deviant phonological processes may be occurring in conjunction with the target process. A complete initial assessment of a child's sound system as well as ongoing probes during the treatment program would be beneficial for providing the most efficient and effective remediation program.

Research Implications

Future studies designed to address the issue of generalization of an underlying feature from treated to untreated sounds within the same feature class would be beneficial. Single-subject studies are valuable in providing the beginning of a theoretical basis for making sound decisions about remediation targets but each, by itself cannot accomplish what a study with a greater number of subjects can. Larger numbers of subjects helps to provide statistically sound results that can be 
applied to the general population.

some questions that have been raised by this thesis could be further explored. In this study, the feature of stridency was targeted through teaching the phoneme $/ \mathrm{s} /$, a voiceless sound. Would there be a difference in outcome if a voiced strident, or two stridents, voiced and voiceless, were chosen as the treatment target(s)? In addition, are some sounds acquired more readily in one word position than another?

Another question resulting from this study addresses the control sounds. One control sound (/w/) improved; the other $(/ d /)$ did not change. Because only those two sounds were monitored, a statement about changes to the child's sound system as a whole, could not be made. It would be interesting to know how the entire sound system of a child is affected by treatment.

This single-subject study has provided support to the theory that remediating one sound can lead to the improvement of other sounds sharing the same underlying feature. Most of the untreated strident phonemes did improve spontaneously. However, one of the control sounds from a separate feature class also improved. The reason for this can only be speculated. Hence, questions still remain, and only through continued research and compiling of knowledge will the most efficient and 
effective treatment targets for highly unintelligible children be determined. 


\section{References}

Blache, S. E., Parsons, C. L., \& Humphreys, J. M. (1981). A Minimal-word-pair model for teaching the linguistic significance of distinctive feature properties. Journal of Speech and Hearing Disorders, 46, 291-296.

Chomsky, M., \& Halle, M. (1968). The sound pattern of English. New York: Harper \& Row.

Costel10, J., \& Onstine, J. (1976). The modification of multiple articulation errors based on distinctive feature theory. Journal of Speech and Hearing Disorders, 41, 199-215.

Creaghead, N. A., Newman, P. W., \& Secord, W. A. (1989). Assessment and remediation of articulatory and phonological disorders. New York: Macmillan.

Dinnsen, D. A., Chin, S. B., Elbert, M., \& Powel1, T. W. (1990) Some constraints on functionaliy disordered phonologies: Phonetic inventories and phonotactics. Journal of Speech and Hearing Research, $33,28-37$

Dunn, L. M., \& Dunn, L. M. (1981). Peabody Picture Vocabulary Test-Revised. Circle Pines, MN: American Guidance Service. 
Hodson, B. W. (1994). Determining phonological intervention priorities. In children's phonology disorders: Pathways and patterns. Rockville, MD: American Speech-Language-Hearing Association.

Hodson, B. W., \& Paden, E. P. (1991). Targeting intelligible speech (2nd ed.). Austin, TX: Pro-ed.

McDonald, E. (1964a). Articulation testing and treatment: A sensory-motor approach. Pittsburgh: Stanwix.

McDonald, E. (1964b). The Deep Test of Articulation. Pittsburgh: Stanwix.

McReynolds, L. V., \& Bennett, S. (1972).

Distinctive feature generalization in articulation training. Journal of Speech and Hearing Disorders, 37 , $462-470$

McReynolds, L. V., \& Huston, K., (1971). A distinctive feature analysis of children's misarticulations. Journal of Speech and Hearing Disorders, $36,155-166$.

Powe11, T. W., Elbert, M., \& Dinnsen, D. A. (1991). stimulability as a factor in the phonological generalization of misarticulating preschool children. Journal of Speech and Hearing Research, 34, 1318-1328. 
Ruder, K. F., \& Bunce, B. H. (1981). Articulation therapy using distinctive feature analysis to structure the training program: Two case studies. Journal of Speech and Hearing Disorders, 46, 59-65.

Sander, E. (1972). When are speech sounds learned? Journal of Speech and Hearing Disorders, 37, 55-63.

Tyler, A. A., Edwards, M. L., \& Saxman, J. H. (1987). Clinical application of two phonologically based treatment procedures. Journal of Speech and Hearing Disorders, 52, 393-409.

Van Riper, C. (1939). Speech correction: Priniciples and methods. New York: Prentice Hal1. 
APPENDIX A

Production-Practice Words

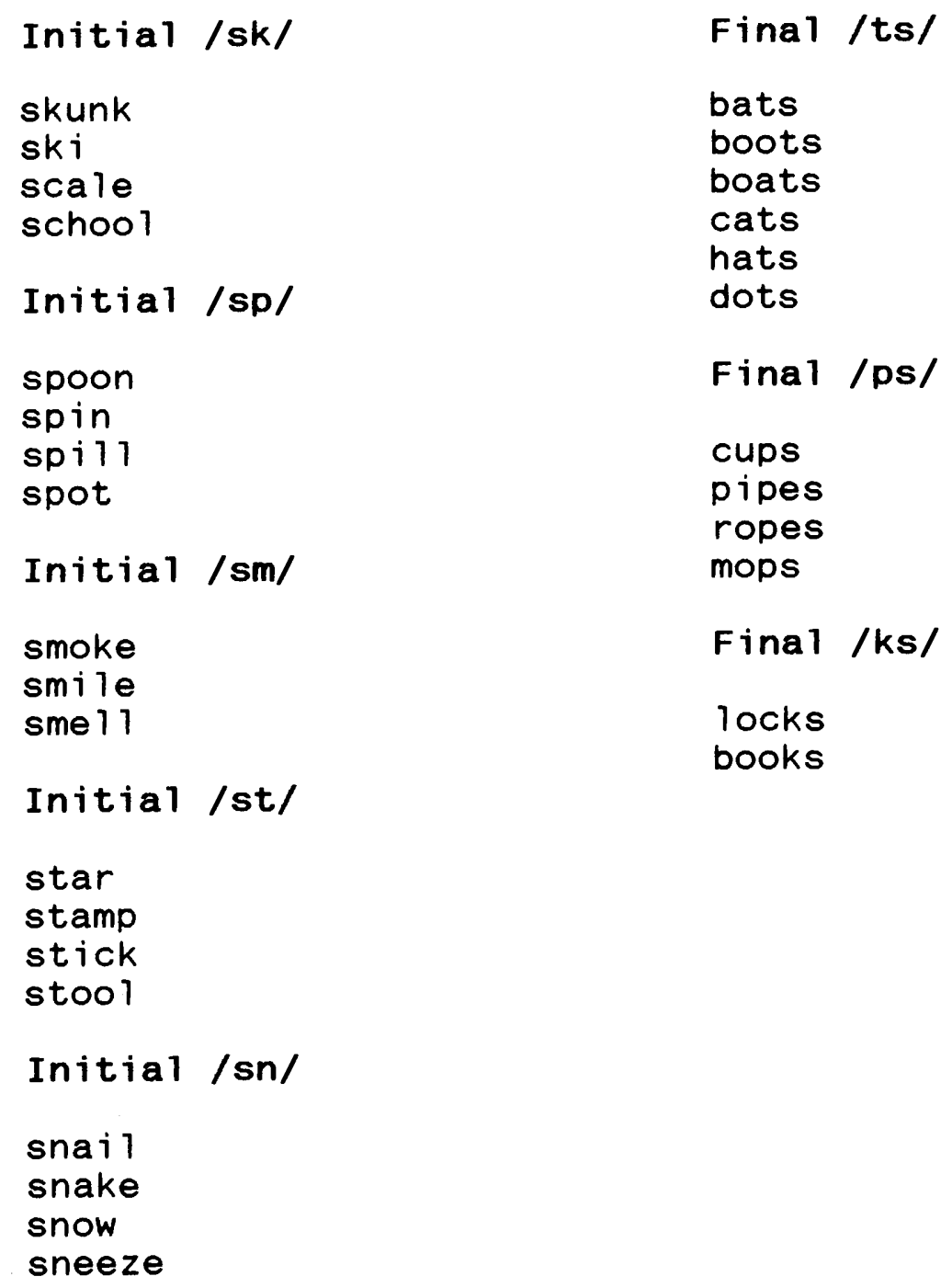




\section{APPENDIX B}

Probe Words

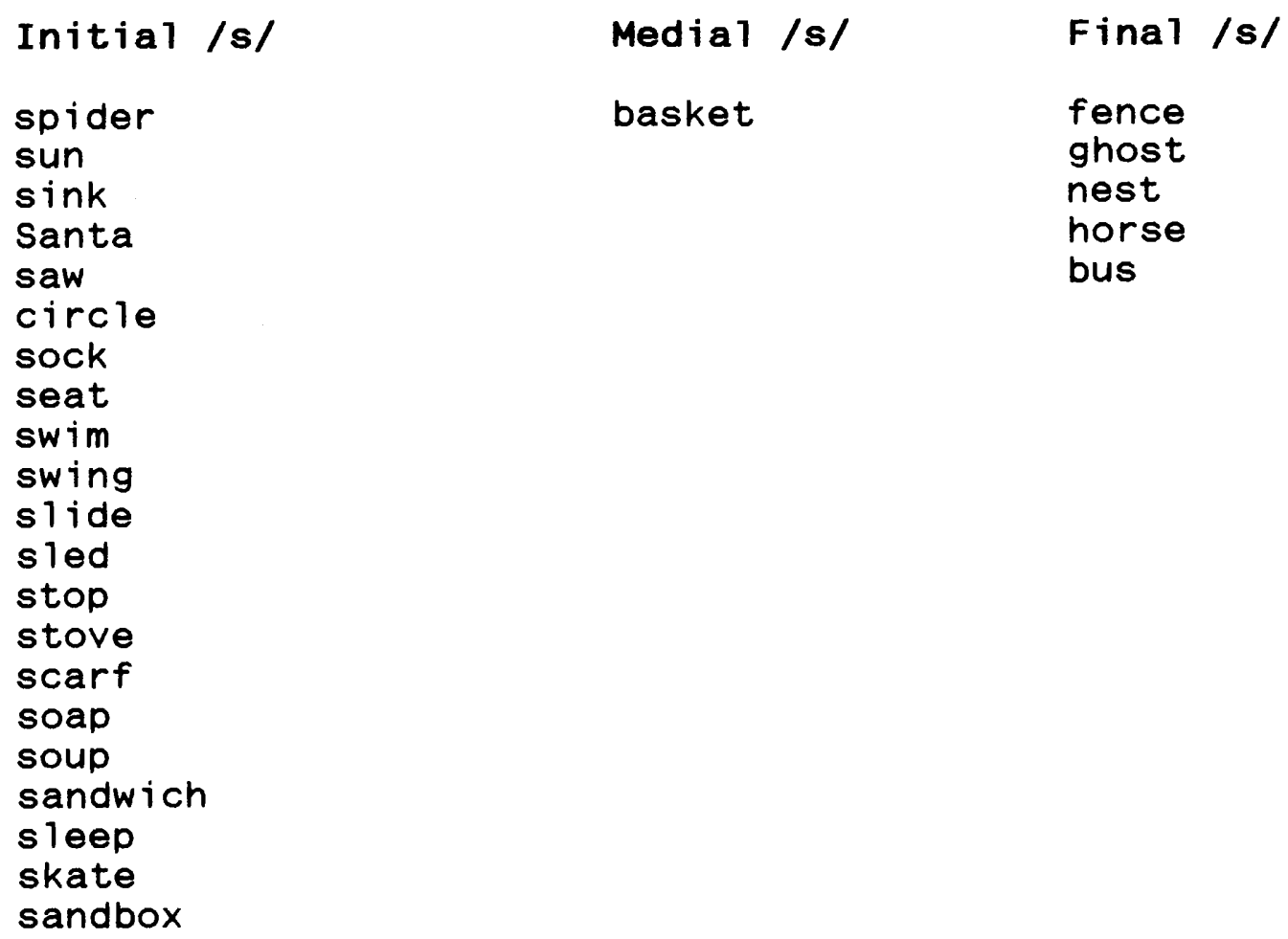


APPENDIX C

I, , agree to allow my

child , to participate in this

research project on the generalization of correct production training of sounds from trained to untrained sounds. In addition, my child has verbally agreed to participate in this research project. I understand that in order for my child to participate in this study he/she will need to pass a hearing screening and an oral-peripheral exam (i.e., observation of the parts of the mouth and movement of the mouth).

I understand that the study involves saying words represented by pictures or objects several times throughout a treatment session and at home once a day. Furthermore, it is understood that my child will be asked to respond to periodic tests of 10 to 25 minutes in length that require him/her to name objects/pictures. I agree to bring my child to the speech and Hearing clinic at Portland State University for 50 minute treatment sessions, 2 to 3 times a week for 8 weeks or a total of 24 treatment sessions. Kathleen Ozanich has informed me that the study will be terminated when my child is able to correctly say the trained sound in the 20 probe words.

I understand that, because of this study, my child 
may feel some slight frustration if he/she is unable to say the training and/or test words correctly.

Kathleen Ozanich has told me that the purpose of this study is to assess whether treating one sound in error will generalize to other untreated error sounds. My child may not receive any direct benefit from taking part in this study, but the study may help to increase knowledge that may help others in the future.

Kathleen Ozanich has offered to answer any questions I have about the study and what my child is expected to do. I understand that the results of this study may be used for publication or for scientific purposes, but all information about me and my child will be kept confidential and our identities will remain anonymous.

I understand that my child does not have to take part in this study, and that we may withdraw from this study at any time without affecting our relationship with Portland State University.

I have read and understand the foregoing information.

Date Signature

If you experience problems that are the result of your participation in this study, please contact the chair of the Human Subjects Research and Review Committee, Office 
of Graduate Studies and Research, 105 Neuberger Ha11, Portland State University, 725-3923. 
APPENDIX D

Thes is Approval

\section{OFFICE OF GRADUATE STUDIES AND RESEARCH}

Research and Sponsored Projects

DATE: $\quad$ July 25,1996

TO: $\quad$ REOM: $\quad \begin{aligned} & \text { Kathleen Ozanich } \\ & \text { Laurie Skokan, Chair, HSRRC 1995-96 } \\ & \begin{array}{l}\text { HSRRC approval of changes to your project(s), "The Generalization of Stridency } \\ \text { From Treated to Untreated Misarticulated Phonemes" }\end{array}\end{aligned}$

In response to your request for an approval of change in your original HSRRC application, the Human Subjects Research Review Committee has filed your addendum(s) in your original application file(s). We note that there are no major alterations in the research plan originally proposed.

The Committee is satisfied that your provisions for protecting the rights and welfare of all subjects participating in the research are adequate. We would like to thank you for notifying the committee of your change(s), and ask that you document this as your approval for your applicaton(s). 